\title{
Improvement of Parkinsonian features correlate with high plasma levodopa values after broad bean (Vicia faba) consumption
}

\author{
J M Rabey, Y Vered, H Shabtai, E Graff, A D Korczyn
}

\begin{abstract}
Five healthy volunteers and six patients with Parkinson's disease (PD) ate $250 \mathrm{~g}$ cooked broad beans after 12 hours without treatment. During the next four hours a substantial clinical improvement was noted, three patients showed severe dyskinesias, and plasma levodopa concentrations rose.
\end{abstract}

(F Neurol Neurosurg Psychiatry 1992;55:725-727)

Levodopa was identified in the seedlings, pods and beans of the broad bean (Vicia faba-VF) by Guggenheim in $1913 .^{1}$ Although anecdotal cases of PD improvement after ingesting broad beans have been presented, ${ }^{2}$ we are not aware of any studies which have systematically examined this question.

\section{Patients and methods}

Six patients with PD participated in the study, after signing written consent (mean age 63.5 years; mean disease duration 13 years; stage III, Hoehn and Yahr scale; mean daily dose of broad beans $541 \mathrm{mg}$ and $54 \cdot 1 \mathrm{mg}$ carbidopa; 3 also took bromocriptine and 3 took lisuride hydrogen maleate (table 1). Three of the patients also had moderate drug-induced dyskinesia. Five healthy volunteers (mean age 49 years) also participated in the study after giving their written consent. The trial was approved by the hospital Helsinki Committee.

After 12 hours off medication, six PD patients had breakfast at 7 am consisting of tea or coffee with biscuits or a slice of bread. At $8-8.30$ am they ate $250 \mathrm{~g}$ of cooked VF. Blood samples were obtained before eating VF (time

Table 1 Patients' characteristics

\begin{tabular}{|c|c|c|c|c|c|}
\hline Patient & Sexlage & $\begin{array}{l}\text { Disease } \\
\text { duration }(y)\end{array}$ & $\begin{array}{l}\text { Stage } \\
\text { (Hoehn-Yahr) }\end{array}$ & $\begin{array}{l}\text { Treatment } \\
\text { (mean daily dose } \mathrm{mg} \text { ) }\end{array}$ & Dyskinesio \\
\hline 1 & $\mathrm{M} / 60$ & 9 & III & $\begin{array}{r}500 \mathrm{LD} \\
10 \mathrm{Bro}\end{array}$ & +++ \\
\hline 2 & M/65 & 10 & III & $\begin{array}{r}750 \mathrm{LD} \\
15 \text { Bro }\end{array}$ & +++ \\
\hline 3 & $\mathrm{M} / 70$ & 15 & III & $\begin{array}{c}500 \mathrm{LD} \\
3 \mathrm{Lis}\end{array}$ & ++ \\
\hline 4 & $F / 56$ & 12 & III & $\begin{array}{r}625 \mathrm{LD} \\
1 \mathrm{Lis}\end{array}$ & \\
\hline 5 & M/66 & 20 & III & $\begin{array}{r}500 \mathrm{LD} \\
2 \mathrm{Lis}\end{array}$ & \\
\hline 6 & $F / 64$ & 12 & III & $\begin{array}{l}375 \text { LD } \\
20 \text { Bro }\end{array}$ & \\
\hline
\end{tabular}

LD_levodopa; Bro-bromocriptine; Lis-lisuride.

Dyskinesia (see method).

Neurology and $\mathrm{Clin}$ Elias Sourasky Medical Center and Medicine, Tel-Aviv $Y$ Vered

H Shabtai

A D Korczyn

Dr Rabey, Department of Neurology, Ichilov Hospital, 64239 , Israel

Received 19 August 1991 Accepted 23 October 1991.
0 ) and every 30 minutes thereafter for four hours. Clinical evaluation was scored according to the Webster scale. ${ }^{3}$ Dyskinesia was evaluated on a separate scale ranging from 0 (no dyskinesia) to 4 (severe dyskinesia). Five days later, the same patients were given orally $125 \mathrm{mg}$ levodopa plus $12.5 \mathrm{mg}$ carbidopa at time 0 , after 12 hours off medication. Blood samples were then obtained at time 0 and each 30 minutes thereafter for four hours. The clinical evaluation was performed as described above. Five healthy volunteers also ate $250 \mathrm{~g}$ cooked VF at 8-8.30 am. Blood samples were obtained at time 0 and every 30 minutes for four hours.

DOPA MEASUREMENTS

Plasma concentrations of levodopa were determined by an HPLC-ECD method. ${ }^{4}$ Catecholamines were absorbed onto acid washed alumina at $\mathrm{pH} 8.5$ directly from plasma. After being shaken with the alumina, the residue plasma was aspirated. Catecholamines were then eluted from the alumina by a small volume of $0 \cdot 1 \mathrm{M} \mathrm{HC10}$. The HPLC system consisted of an LDC/Milton Roy high pressure pump, a rheodyne injector, and RP chromatographic column (BAS ODS column, $4 \times 250 \mathrm{~mm}, 5 \mathrm{mu}$ ) and an electrochemical detector (LC-4, BAS) equipped with a TL-5 glassy carbon electrode. The applied potential at the working electrode was $+0.64 \mathrm{~V}$. The mobile phase consisted of monochloroacetate buffer containing $2 \mathrm{mM}$ EDTA and an ion pair agent (SOS, $50 \mathrm{mg} / \mathrm{L}$ ). The lower limit of detection was $200 \mathrm{pg} / \mathrm{ml}$ and the intertest coefficient of variation was $5 \%$.

Statistical analysis for the comparison of clinical performance and levodopa plasma levels in the PD group while eating VF versus levodopa was performed using Wilcoxon and Student's paired $t$ tests.

\section{Results}

PD patients showed a significant improvement in their motor features after eating VF which was similar to the improvement measured after receiving $125 \mathrm{mg}$ of levodopa plus $12.5 \mathrm{mg}$ of carbidopa (table 2). Moreover, in three patients we observed after VF ingestion severe dyskinesias which were similar to those observed after levodopa administration (table 3). Plasma levodopa levels increased substantially (although somewhat less) after the broad beans compared with levodopa in PD 
Table 2 Cumulative Motor Score (Webster) $(n=6)$

\begin{tabular}{lrrrrrrrr}
\hline Minutes/ & 0 & 30 & 60 & 90 & 120 & 150 & 180 & 240 \\
\hline VF & 140 & 114 & 97 & 95 & 96 & 105 & 123 & 130 \\
LD & 136 & 119 & 99 & 100 & 102 & 115 & 124 & 132 \\
\hline VF = Vicia faba ingestion. \\
LD = 125 mg levodopa + $12.5 \mathrm{mg}$ DCI. \\
Table 3 \\
Cumulative Dyskinesia Score $(n=3)$
\end{tabular}

\begin{tabular}{lrrrrrrrr}
\hline Minutes/ & 0 & 30 & 60 & 90 & 120 & 150 & 180 & 240 \\
\hline VF & 0 & 6 & 12 & 8 & 4 & 2 & 0 & 0 \\
LD & 0 & 5 & 12 & 10 & 6 & 0 & 0 & 0 \\
\hline VF = Vicia faba ingestion. & & \\
LD $=125 \mathrm{mg}$ levodopa + & $12.5 \mathrm{mg}$ DCI.
\end{tabular}

patients (figure 1). The mean (SD) Cmax was also not significantly different ([Cmax (VF) $0.84(0.2) \mu \mathrm{g} / \mathrm{ml}$ vs $\mathrm{Cmax}$ (levodopa) 1.22 $(0.31) \mu \mathrm{g}])$. The mean (SD) AUC was similar ([VF $2.95(0.85) \mu \mathrm{g} / \mathrm{ml} / \mathrm{H}^{\mathrm{o}-4}$ vs levodopa 3.21

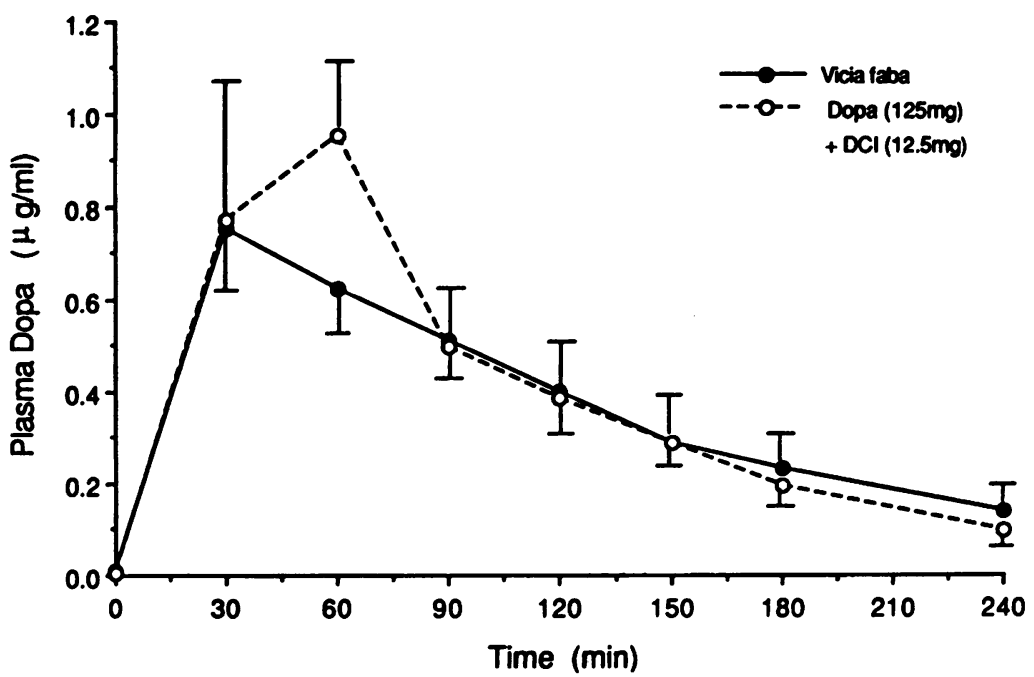

Figure 1 Plasma levodopa levels measured after the ingestion of VF and levodopa in six $P D$ patients.

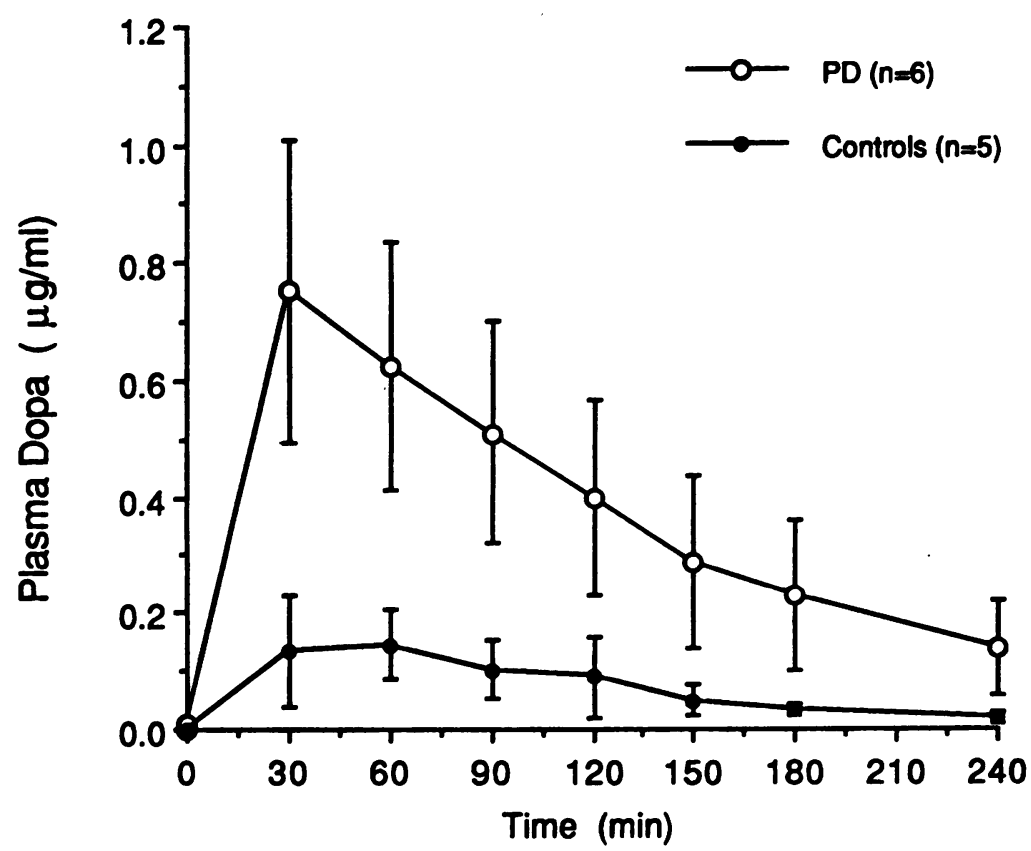

Figure 2 Plasma levodopa levels measured after the ingestion of VF in six PD patients and five healthy volunteers. $\left.\left.(0 \cdot 59) \mu \mathrm{g} / \mathrm{ml} / \mathrm{H}^{\circ-4}\right]\right)$. The mean $\mathrm{Tmax}$ was also similar.

Five volunteers also showed an increase in plasma levodopa levels after eating broad beans which were similar although considerably lower than the levels measured in PD patients after they had eaten broad beans (fig 2 ).

\section{Discussion}

Three natural potential precursors for dopamine synthesis which can be supplied in the diet, already exist in the brain: phenylalanine, tyrosine and levodopa. Phenylalanine hydroxylase has not been found in the brain ${ }^{5}$ but phenylalanine may be a substrate for tyrosine hydroxylase and can be converted to tyrosine by this enzyme. ${ }^{\circ}$ High doses of phenylalanine, however, reduce catecholamine synthesis, perhaps due to inhibition of tyrosine hydroxylation. $^{78}$ Several investigators found that dl-phenylalanine either had no effect or exacerbated Parkinsonism.9 ${ }^{9}$

Tyrosine is the normal precursor for catecholamine synthesis. Tyrosine administration does not affect dopamine synthesis in normal animals. ${ }^{7}$ However, if the dopaminergic system is lesioned, the increased firing rate of the remaining neurons will require more tyrosine and in this case, tyrosine administration will enhance dopamine synthesis. ${ }^{112}$ Administration of tyrosine to Parkinsonian patients increased the CSF concentration of the dopamine metabolite homovanillic acid (HVA) by $75 \% .{ }^{13}$ If, however, tyrosine hydroxylase was severely depleted, as in more advanced Parkinsonism, tyrosine addition would be of little benefit.

The levodopa content of the normal diet is very low or absent. ${ }^{14}$ The low concentration of levodopa found in the plasma apparently reflects the activity of peripheral tyrosine hydroxylase in sympathetic neurons rather than dietary intake. ${ }^{15}$

In our study, plasma levodopa levels induced in PD patients were higher than the levels measured in healthy volunteers after eating the same amount of broad beans. This difference may be due to the previous treatment of the patients with carbidopa, a potent peripheral decarboxylase inhibitor with a prolonged plasma half-life. ${ }^{16}$

1 Guggenheim M. Dioxyphenylalanain, eine neue Aminosaeure aus Vicia faba. Zeitschr Physiol Chemie 1913; 88:276-84.

2 Spengos M, Vassilopoulos D. Improvement of Parkinson's disease after Vicia Faba consumption. Ninth Int Symposium on Parkinson's disease Jerusalem, Israel. Abs 1988:46.

3 Webster DD. Clinical analysis of the disability in Parkinson's disease. Mod Treat 1968;5:257-82.

4 Shoup RE, Keife J. Plasma catecholamines assayed conveniently and rapidly by LCEC. Current Separation 1980;3:1-30.

5 Tourian A, Groddard J, Puck TT. Phenylalanine hydrox ylase activity in mammalian cells. $\mathcal{f}$ Cell Physiol 1969,

6 Kaufman S. Properties of the pterin-dependent aromatic amino acid hydroxylase. Ciba Found Symp 1974; 22:85-108.

7 Gibson CJ, Deikel SM, Young SN, Binik YM. Behavioura and biochemical effects of tryptophan, tyrosine and phenylalanine in mice. Psychopharmacology 1982; 76:118-21

8 Nagatsu T, Levitt $M$, Vdenfriend $S$. Tyrosine hydroxylase: 
Chem 1964;239:210-17.

9 Cotzias GC, Van Woert MH, Schiffer LM. Aromatic amino acids and modification of parkinsonism. $N$ Engl $\mathfrak{f}$ Med 1967;276:374-9.

10 Granerus AK, Jagenburg R, Roger S, Svanborg A. Phenylalanine absorption and metabolism in parkinsonian alanine absorption and 19

11 Agid Y, Savoy F, Glavinolli J. Hyperactivity of remaining dopaminergic neurons after partial destruction of the
nigrostriatal dopaminergic synthesis in the rat. Nature nigrostriatal dopaminergic s
(New Biol) 1973;245:150-1.

12 Melamed E, Hefti F, Wurtman RJ. Tyrosine administration increases striatal dopamine release in rats with partial
nigrostriatal lesions. Proc Natl Acad Sci 1980;77:4305-9.
13 Growdon JH, Melamed E. Effects of oral 1-tyrosine administration on CSF tyrosine and HVA levels in patients with Parkinson's disease. Neurology 1980;30:396,

14 Hoeldtke R, Baliga I, Essenberg P, Wurtman RJ. Dihydroxyphenylalanine in rat food containing wheat and oats. Science 1972;175:761-2.

15 Eisnhofer G, Goldstein DS, Ropchak TG, Kopin IJ. Source and physiological significance of plasma 3,4 -dihydroxyphenylalanine in the rat. $\mathcal{F}$ Neurochem 1988 ; 51:1204-13.

16 Vickers S, Stuart EK, Bianchine JR, et al. Metabolism of carbidopa, an aromatic amino acid decarboxylase inhibitor in the rat, dog, rhesus monkey and man. Drug Metab itor in the rat, dog, rhes
Dispos $1974 ; 2: 9-22$.

\section{Neurological stamp}

\section{Franciscus de le Boë or Sylvius 1614-72}

The chief interest of Franciscus Sylvius was alchemy. $\mathrm{He}$ was one of the founders of the iatrochemical school which thought that all phenomena of life and disease were based on chemical action. (He should not be confused with Jacques Dubois, 1478-1555, also called Sylvius, who was an instructor of anatomy in Paris).

Franciscus Sylvius was considered a great teacher of his time and was among the first to introduce ward instruction. His name is linked eponymously to the Sylvian fissure, but his relationship to this structure is obscure. The aqueduct between the third and fourth ventricules has been previously attributed to both Jacobus and Franciscus Sylvius but it had been described long before by others.

Sylvius noted that some tremors were always present but others appeared only with movement. He explored the concept of thermal and tactile senses, had an understanding of ductless glands and was one of the first to propose that the pancreas produced a juice, which together with saliva and a form of fermentation, aided digestion. He was the first to describe tubercles and the process of cavitation. The Netherlands honoured him with this stamp in 1937 (Stanley Gibbons no 470, Scott no B95). 